\title{
Analysis of e-Learning Environment for Geography: Opportunities for Personalized Active Learning
}

\author{
Štefan KAROLČÍIK ${ }^{1}$, Inga ZILINSKIENE ${ }^{2}$, Asta SLOTKIENE $^{3}$, \\ Elena ČIPKOVÁ ${ }^{1}$ \\ ${ }^{1}$ Department of Department of Didactics in Science, Psychology and Pedagogy, \\ Faculty of Natural Sciences of Comenius University in Bratislava, \\ 8 Ilkovicova Str., 84215 Bratislava, Slovakia \\ ${ }^{2}$ Department of Economics and Business, Mykolas Romeris University, \\ 20 Ateities Str., 08303 Vilnius, Lithuania \\ ${ }^{3}$ Department of Information Systems, Vilnius Gediminas Technical University, \\ 11 Sauletekio Ave., 10223 Vilnius, Lithuania \\ stefan.karolcik@uniba.sk; inga.zilinskiene@mruni.eu; \\ slotkiene@tf.su.lt; elena.cipkova@uniba.sk
}

\begin{abstract}
The rapid changes in technologies for representing learning content impact the modern concept of e-learning. They enable the implementation of personalized learning, development of a friendly, flexible and simulation-based learning environment. In this paper, the e-learning environment for Geography was analysed. In order to implement personalized active learning in Geography teaching and learning, the requirements of an adaptive tool for Geography teaching and learning are discussed and the theoretical framework for personalized e-learning environment is proposed. Based on previous experimental pedagogical research (carried out in Slovakia between 2008-2013 within the national project "Modernisation of the Educational Process in Elementary and Secondary Schools"), a new geospatial technological approach and theoretical framework for active learning process is discussed, and the prototype of a new Mapker for Geography teaching and learning is presented.
\end{abstract}

Keywords: e-learning, personalized active learning, Geography, geospatial technologies, Mapker

\section{Introduction}

The main aim of educational technologies is to ensure not only flexibility, effectiveness, the efficiency of e-learning, but to be organized in modern fashion as well. Despite these requirements it must combine serious learning and gamification in order to be attractive to as many learners as possible, i.e. it can be stated that e-learning must provide personalized active learning. Although personalized e-learning can be analysed from different perspectives, the paper presents a new framework which will be incorporated into an e-learning environment for Geography, based on the personalization - not only of the content but of the activities as well. Personalized learning refers to efforts of tailoring 
education to meet different student needs, e.g. different knowledge levels, skills, ages, etc. Active learning is any learning activity in which the student participates or interacts with the learning process, as opposed to passively taking in the information, working not only about the content, but within the content, e.g. including games, simulations, etc. Based on these two concepts, personalized active learning is introduced.

Literature review on e-Learning Environments for Geography reveals some important findings on requirements to be met in order to fulfil unique and subject-based needs, not only of the students but those of the teachers as well. The research which had been carried out (Karolč́́k, 2007, 2010), included a questionnaire survey and discussions with Slovak Geography teachers. It confirmed that the biggest problem, significantly limiting the use of existing geospatial technology containing professional map outputs, is an unnecessarily large database of the provided information and missing Slovak localisation. Moreover, their work with software products belonging to the group of available geographic information systems is complicated by the unintelligible user interface, many functions, control elements, and tools.

In this paper, firstly, the e-learning environment for Geography was analysed. Next, main requirements for a new e-learning environment were established. In the third part of the paper, based on scientific research and previous experimental pedagogical research (carried out in Slovakia between 2008-2013 within the national project "Modernisation of the Educational Process in Elementary and Secondary Schools"), both a new theoretical framework for the active learning process and its prototype is presented.

\section{Literature Review}

\subsection{Review of e-Learning Environments for Geography}

Geospatial technologies (GST), such as global positioning systems (GPS) and GPSenabled devices, geographic information systems (GIS) programs, Web-based geographic information systems (GIS), and virtual globes, offer a large number of alternative applications in the learning and teaching process; their educational potential has been already pointed out by several authors and in many conceptual documents (e.g., (National Research Council, 2006), (McClurg and Buss, 2007), (Lee and Bednarz, 2009), (Goodchild and Janelle, 2010), (NGSS Lead States, 2013)). However, the research-based evidence of real and sustained benefits of GST to education and learning is lacking. Existing research in this area has been sparse and fragmented, with no clear plan to provide guidance to aspiring investigators (Baker and Bednarz, 2003; Baker et al., 2012). Lack of research-based evidence for sustained benefits of GST to learning is one hindrance of large-scale implementation of Geospatial Technologies in schools (Baker et al., 2014).

As the list of commercial, as well as freely accessible software applications and technological solutions that might be included in the GST category is huge and cannot be exhaustive, in this paper the analysis of existing solutions was carried out only with selected software applications which have already been implemented in the Geography teaching process and subjected to the verification within the performed research activities. This group of GST includes also virtual globes. Virtual globes contain tools simulating flying above the landscape as if the user were in their own personal spacecraft. At any point, one can zoom, pan, or tilt the Earth view for a 3D perspective 
(Schultz et al., 2008). The best-known virtual globes include NASA WorldWind, ArcGIS Explorer from ESRI, Skyline's TerraExplorer, and, of course, the Google Earth by Google. A special place within the virtual globe products is held by the Marble virtual globe, currently being developed within the KDE Edu project (Table 1).

Table 1. A comparison of several virtual globes

\begin{tabular}{|c|c|c|c|c|}
\hline Virtual globe & Accessibility & $\begin{array}{l}\text { Used for Geography } \\
\text { education }\end{array}$ & $\begin{array}{l}\text { Quality } \\
\text { level* }\end{array}$ & $\begin{array}{l}\text { Personalized } \\
\text { e-learning } * *\end{array}$ \\
\hline Google Earth & $\begin{array}{l}\text { A free online } \\
\text { digital globe } \\
\text { released by } \\
\text { Google Inc }\end{array}$ & $\begin{array}{l}\text { Yes, easy to use, but } \\
\text { complex (Wilson 2008), } \\
\text { (Zhu, Pan \& Gao 2016). }\end{array}$ & high & No \\
\hline $\begin{array}{l}\text { NASA } \\
\text { WorldWind }\end{array}$ & $\begin{array}{l}\text { A free, open } \\
\text { source API }\end{array}$ & $\begin{array}{l}\text { No, too complex } \\
\text { It is a software development } \\
\text { kit that software engineers } \\
\text { can use to build their own } \\
\text { applications (NASA, 2017) }\end{array}$ & average & No \\
\hline $\begin{array}{l}\text { ArcGIS } \\
\text { Explorer from } \\
\text { ESRI }\end{array}$ & $\begin{array}{l}\text { Education free } \\
\text { ArcGIS } \\
\text { Online } \\
\text { organization } \\
\text { accounts }\end{array}$ & $\begin{array}{l}\text { Yes } \\
\text { (Esri 2017b). }\end{array}$ & high & No \\
\hline $\begin{array}{l}\text { Skyline's } \\
\text { TerraExplorer }\end{array}$ & $\begin{array}{l}\text { Free to } \\
\text { download }\end{array}$ & $\begin{array}{l}\text { No, too complex. Enables to } \\
\text { create realistic 3D } \\
\text { visualisations by overlaying } \\
\text { the terrain with unlimited } \\
\text { data layers, 3D models and } \\
\text { virtual objects (Skyline, } \\
\text { 2017). }\end{array}$ & average & No \\
\hline $\begin{array}{l}\text { KDE Edu } \\
\text { project }\end{array}$ & Free & $\begin{array}{l}\text { Yes, (Karolčík, Čipková \& } \\
\text { Mázorová 2016). }\end{array}$ & high & No \\
\hline
\end{tabular}

* For determining Level of quality we used the Concept for the comprehensive evaluation of the quality of educational software (CEELTES) (Karolčík et al., 2015), and according to the results obtained we ranked the software product into one of the levels of personalization very low, low, average, high, very high.

**Personalized e-learning- it was checked if the system personalizes e-learning at any level: content, activity, learning path, performance, etc. 
According to the results presented in the Table 1, it can be stated that although all virtual world tools are free to access for education, and not less than ,average“ level of quality, still all of them lack personalization and some of them are too complex to be applicable in the classroom environment for different ages of students. Some of the systems, like KDE Edu project, ArcGIS Explorer from ESRI and Google Earth tools have been applied for learning and teaching Geography (Karolčík et al., 2016), but as (Jung, 2017) reveals that „Although previous studies have proven the usefulness and effectiveness of geographic information system (GIS) use in the K-12 classroom, the rate of teacher adoption remains low. The identified major barrier to its use is a lack of teachers' background and experience. To solve this limitation, many organisations have provided GIS-related teacher training using various GIS learning materials. However, most materials have been developed without much consideration for the 'users' of these materials."

Despite the undisputable and often also scientific research-verified impact of GST use on thinking, knowledge and information gained by students (Jadallah et al. 2017; Karolčík et al., 2016; Zhu et al., 2016; Bodzin, 2011; Nielsen et al., 2011; Bodzin and Cirucci, 2009; Stahley, 2006), its implementation into a teaching process faces several obstacles in the practice. There are two realities that contribute to the perpetuation of a lack of meaningful technology integration within $\mathrm{K}-12$ social studies settings: a) the lack of professional development programs addressing the needs and challenges of effective e-learning environment integration (Zhao, 2007), and b) the lack of exposure to existing curricular and pedagogical models teachers can use to guide meaningful integration of technology into the curriculum (Doering et al., 2009). However, the implementation of thoughtfully designed, content-specific professional development programs and supporting guidance in exploring technology integration models may help schools and teachers overcome these realities and barriers (Doering at al., 2014). One way to overcome the mentioned obstacles is to develop an e-learning environment for Geography.

\subsection{The requirements for an adaptive tool for Geography}

The most important characteristic of educational software is its primary purpose, the reason for which it was created. The software created particularly for the educational purposes and used by teachers as a tool for teaching, or by students as a tool for learning, can meet this primary precondition (IT232 - Pedagogical Software, 8.2.2012). The development of educational software intended for creating and editing base maps prove the fact that a key element required for the implementation of any software in the process of teaching Geography in schools is the long-lasting, very close, and intensive cooperation with teachers, students, as well as thorough testing of individual versions of the developed software in technical conditions of a school with the standard level of equipment. In general, a teacher's decision to include or not to include particular educational software in the educational agenda is considerably affected by the teacher's expertise and by the availability of high-quality supporting materials in the form of a complex package of methodologies for the appropriate and meaningful incorporation of the software in the teaching process.

In order to implement personalized active learning into Geography teaching and learning, the requirements of an adaptive tool for Geography teaching and learning are discussed next. 
From the technical perspective an adaptive tool for Geography should satisfy these requirements:

1. Educational software should be stable and provide users with high-level technical, technological, and user comfort.

2. Presented digital content, in the form of outline maps, should consider pedagogical and psychological aspects of learning, respect the applicable educational standards, and use the latest data processing technologies.

3. The use of the educational software product should be simple and intuitive. The graphical user interface should be transparent and selected software control tools should be clear and compendious.

4. Provided digital content, in the form of outline maps, should be open, enable printing, saving, sharing, and exporting of created map documents (Karolčík et al., 2015).

From the personalized active learning perspective an adaptive tool for Geography should incorporate the four main components for complex learning (Learning tasks, Supportive Info, Procedural Info and Part-Task Practice) in order to ensure effective and efficient e-learning. (van Merriënboer and Kirschner, 2018). Based on five factors for successful e-learning, the system must personalize e-learning according to students' performance - should create a stable content and activity adaptation algorithm or strategy and ensure:

1. Maximum of Relevance (Does an adaptive tool relate to what your students thought they were going to see? Where did the visitor just arrive from? Which level?)

2. Maximum of Clarity (Does an adaptive tool clearly call-to-action?)

3. Maximum of Urgency (Is there any indication on it that a particular action should or must be taken now?)

4. Minimum of Distraction (Are there elements on your page that could divert your visitor away from the goal? Minimizing distractions such as unnecessary activities, links, and extraneous information will increase students' learning rate.)

From teachers perspective, educational software should be supplemented with various supporting didactic materials, worksheets, and methodological guides on how to work with its digital content correctly (in an adequate and proper manner) and use it meaningfully in the teaching process, e.g. requirements of teachers to supplement the map content with their own signs containing the text descriptions were met by the authors in the prototype of Mapker by supplementing the list of objects in the 'Map Settings' window with the 'User Descriptions' item. A text field for the description of each object displayed in a map can be edited, supplemented, and changed by a user, as required. Besides all of this, it should offer various interactive educational activities supporting the learning and cognition (Karolčík et al., 2015). 


\section{Developing e-Learning Environments for Geography}

\subsection{The theoretical framework for personalized e-learning environment}

Based on the requirements stated in the previous part, the theoretical framework for personalized e-learning environment is proposed. Personalization could be done using different strategies. According to (Knutov et al., 2009), there are three different strategies that distinguish three possible adaptation methods: 1) content adaptation; 2) adaptive representation; 3) adaptive browsing. Personalized learning with Mapker is based on browsing adaptation by producing personalized learning units or learning paths.

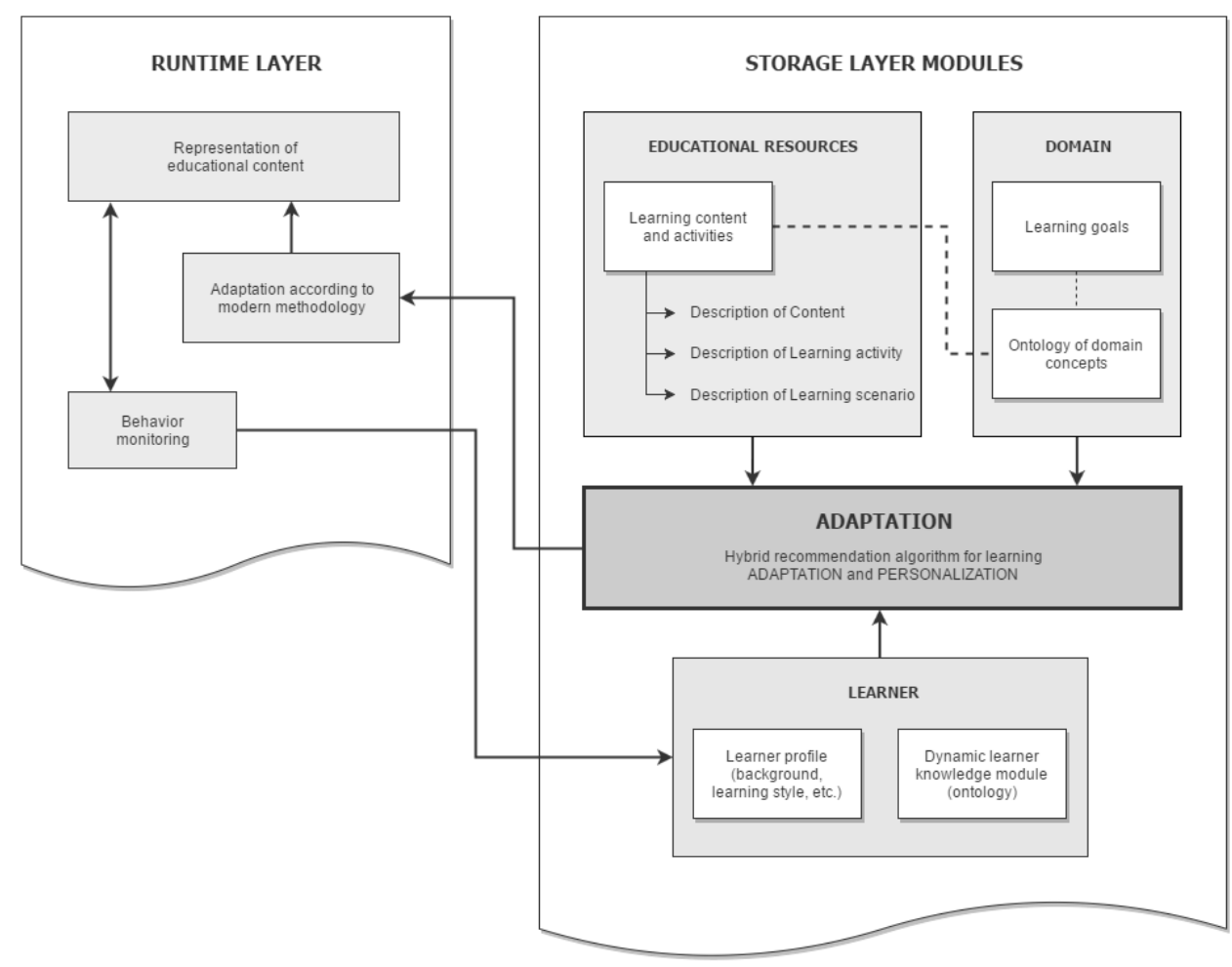

Fig. 1. A proposed approach: a theoretical framework for the development of adaptive Mapker

Runtime layer (Fig. 1.) consists of three functionalities: Monitoring behaviour (in order to provide the most suitable learning content with learning tasks and activities to a student, his/her behaviour on the system should be taken into account), Personalization strategy (an adaptation of learning using previous experience according to the student requirements and needs) and finally the representation of digital content and activities enables personalized active learning of a student.

Storage layer compounds four modules: educational resources, domain, adaptation and learner's module. In this paper the main personalization strategy for personalized active learning is twofold: 1) designing educational resources to ensure an appeal on 
knowledge, skills as well as attitudes (variability of Learning Tasks and Activities (LTA), support, assessment and guidance for LTA); 2) sequencing LTA (for e-learning of longer duration, LTA typically need to be sequenced from simple to complex. Then, topic classes are defined at increasing levels of complexity. In the same topic class, learning tasks are equally complex, show high variability, and gradually decrease available support and guidance.)

\subsubsection{Designing educational resources}

According to findings (Karolčík et al, 2016; van Merriënboer and Kirschner, 2018) design of educational resources is going to be based on four components: Preparation, Presentation, Practice and Performance (Fig. 2).

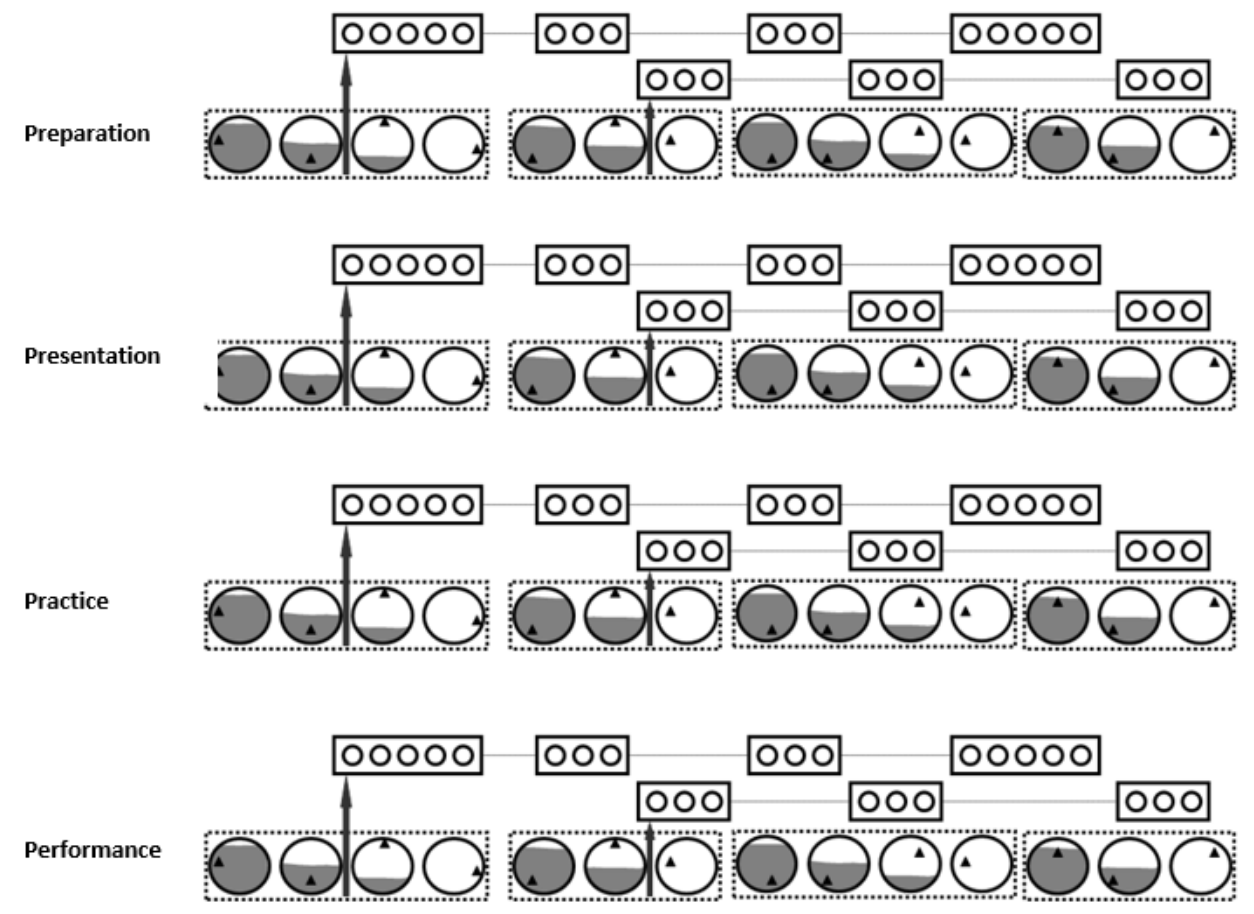

Fig. 2. Four components of educational resources for personalized active learning

The preparation phase includes activities related to the preparation of learning activities, teaching aids, tasks and methodical instructions using the software technology for:

1. arousing curiosity and interest of pupils in a topic,

2. creating a positive atmosphere, motivation to learn and trust in one's own abilities.

The presentation phase includes activities related to the preparation of learning activities, teaching aids, tasks and methodical instructions using the software technology for: 
1. exploring phenomena and processes, discovering new knowledge and putting them into the real-life context;

2. introducing, explaining and clarifying new information and skills applying multiple learning methods;

3. solving problems and applying the elements of cooperative and collaborative learning;

4. as well as integrating new information and skills into a pupil's knowledge.

The practice phase includes activities related to the preparation of learning activities, teaching aids, tasks and methodical instructions using the software technology for:

1. assessing the practical use of the acquired knowledge, skills and competencies,

2. playing quizzes, organizing competitions and undertaking tasks that utilize the elements of active learning;

3. assessing the importance and evaluation of the acquired knowledge.

The performance phase includes teachers' activities related to the preparation of learning activities, teaching aids, tasks and methodical instructions using the software technology for:

1. the creation of outputs usable in real life;

2. extending the knowledge and experience gained;

3. practical use of the acquired knowledge.

Each component should comprise a set of content, tasks, activities, etc. In Fig. 2 learning tasks and activities are indicated as circles. They can be problems that must be solved by the learners, a professional task that needs to be performed, cases that must be studied, projects that are conducted by small groups of students, and so forth. Learning tasks drive learning from concrete experiences or 'learning by doing'. Variability of LTA is indicated by the small triangles at different positions in the learning tasks. Support and guidance are indicated by the filling of the circles. As it was stated, learning tasks typically need to be sequenced from simple to complex. Then, topics are defined at increasing levels of complexity. In Fig. 2, task classes are indicated by dotted rectangles around a set of equally complex learning tasks. The series of small circles indicate help for learners to automate selected routine aspects of learning tasks, provides ample repetition and immediate corrective feedback. Having the design of educational resources stated sequencing of LTA based on learner's information can be presented.

The main principles to design learning task and activities are based on ScopeCommonality-Variability analysis (Niu et al, 2009) of the subject topic. Scope, commonality, and variability (SCV) analysis gives software engineers a systematic way of thinking about and identifying the subject they are creating. The scope defines the topic of the subject. Commonality applies the same tasks of learning path that are valid across all his learning objects. Variability describes the different activities or tasks of the learning process for all learning paths. We will illustrate the meaning of commonality and variability with a simple example. For example, we have a learning topic „, Europe Mountain Massifs “(Scope). This topic has one property of the subject topic - one mountain massif includes several Europe Countries (Commonality). This property will gain different values depending on the purpose or the kind of topic (Variability). For example, in the same learning paths, we design LO (Learning Object) about the same mountain massif (e.g. Alps) and this massif includes several Europe Countries. Another LO could be designed across the same Countries, but with different mountain massifs. In 
this case, we design a regarding commonality principle. But, we apply the variability principle, if the same LO is involved in various activities (in different learning path: preparation, presentation, practice, performance): to mark mountain massifs by the size/to order the mountain by the height, to select countries by the same or different mountain massifs, etc.

The design of LTA must be based on the commonality and variability principles. The process of LTA design consists of these steps:

1. Identification of the learning topic.

2. Each topic is analysed and LOs created. For tasks and activities of LO creation we must apply a couple of rules:

2.1 In the same learning path to select tasks and activities, which have similar commonality value.

2.2 Different learning paths are designed by variability value of tasks and activities.

2.3 The LO on the same topic has only one main purpose and no more than 9 tasks or activities.

\subsubsection{Sequencing Learning Tasks and Activities (LTA)}

The review of the literature shows that personalized learning is more effective than "non-personalized", and looking at it from the technological aspect, it can be implemented by designing and developing adaptive e-learning systems or integral components for non-adaptive systems, e.g. course management systems. It can be found

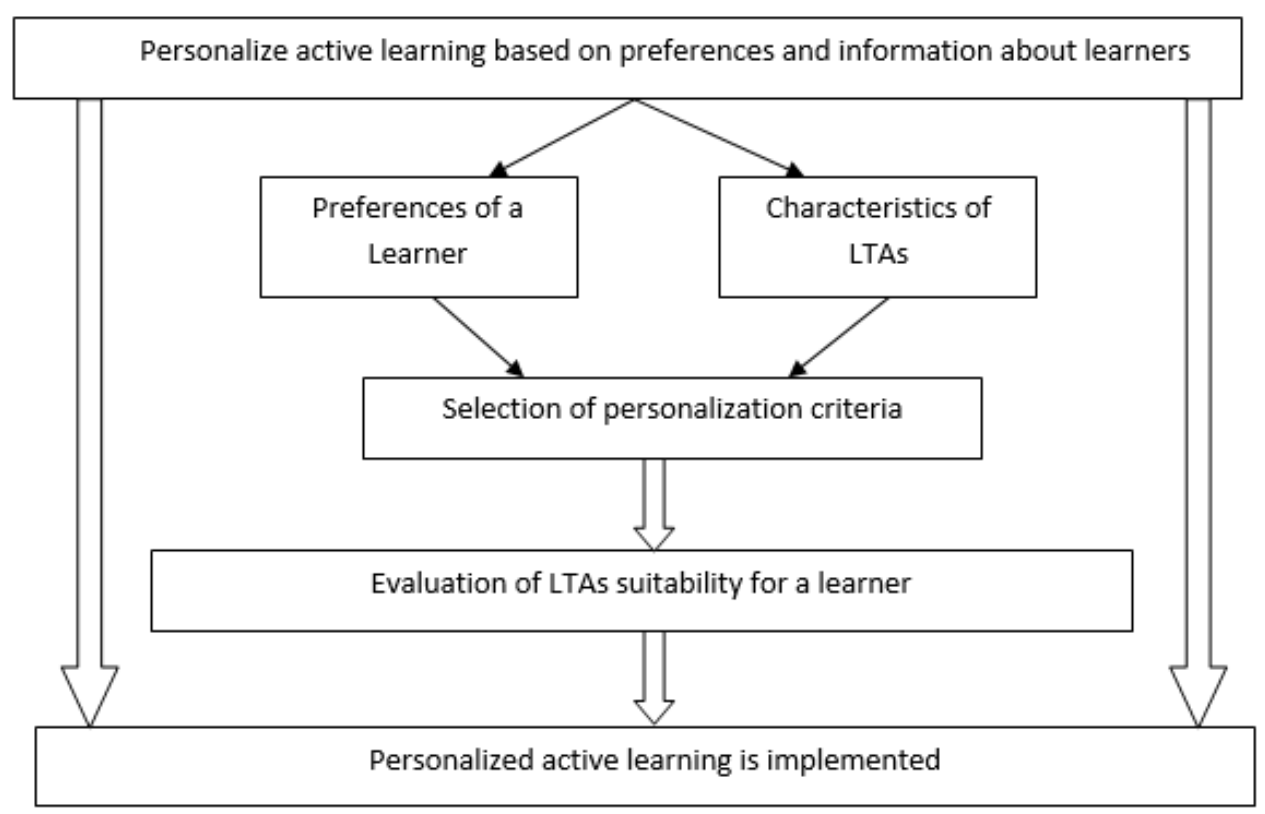

Fig. 3. The initial schema of the information based adaptive algorithm 
that different approaches to e-learning personalization have been applied so far. Hummel et al. (2007) classify personalization methods into two groups: 1) Information-based approaches - they comprise learning technology standardization, metadata, and application of semantic web and 2) social-based approaches - usually data mining, collaborative filtering methods, etc.

The adaptive algorithm for personalized active learning is still under research and will follow the information-based approach.

\subsection{The Prototype of a new Mapker for Personalized Active Learning}

In this part, the prototype of a Mapker for Geography teaching and learning is presented. Since 2006, the Mapker 3.0 educational software is a digital teaching aid, continuously developed in the school practice by teachers and tested by students, designed specifically for the purpose of teaching Geography. The Mapker 3.0 (www.mapker.sk) educational software offers a modern and simple method to users how to adjust base outline maps that were processed in order to provide a wide range of the most frequently used map objects and layers. The basic offer contains maps of Slovakia, Czech Republic, Africa, Australia, Asia, Europe, South and Northern America, supplemented with the cartographic representation of the entire Earth surface, titled the World. The Mapker 3.0

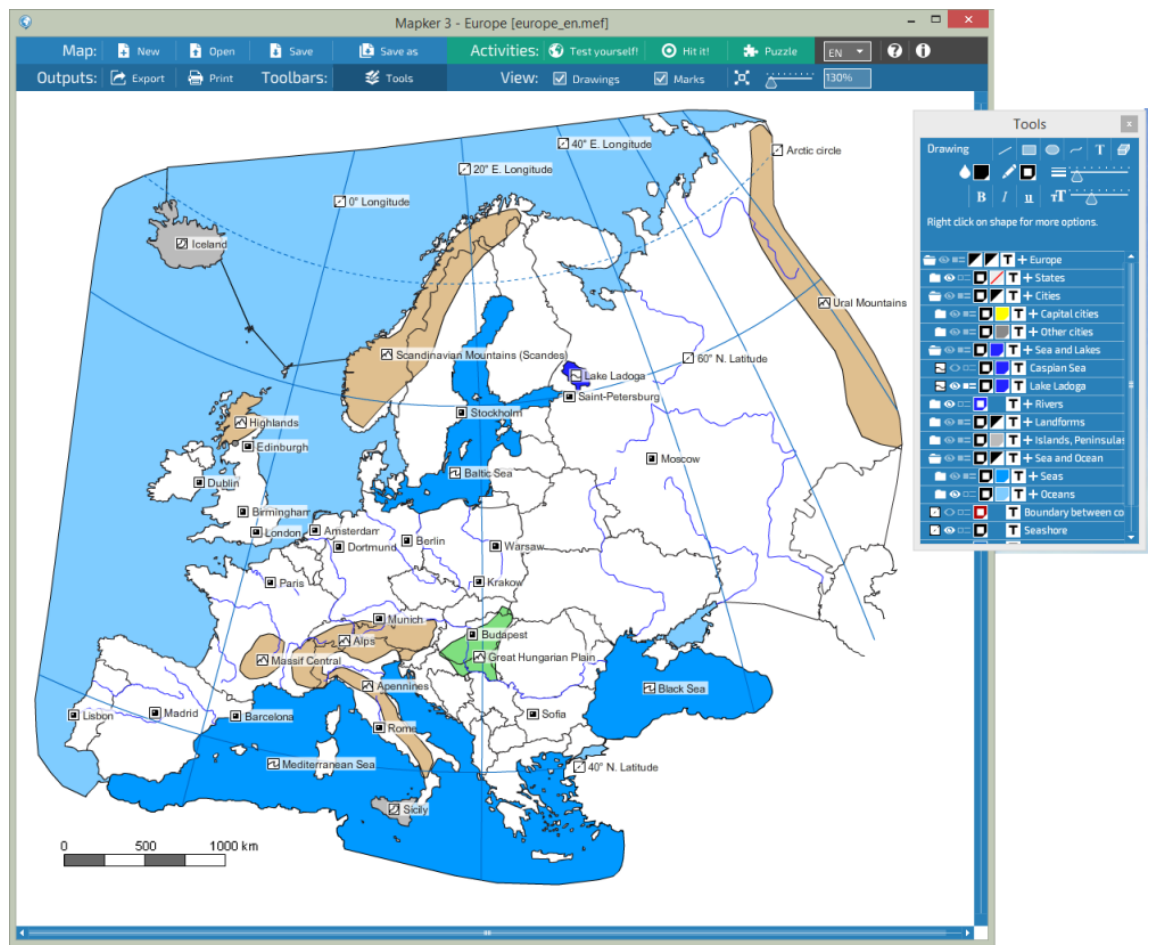

Fig. 4. The graphical user interface of the prototype of Mapker

significantly simplifies the creation of user's own outline maps and map cut-outs. A created map may be saved on a computer hard disc, reloaded, further modified, 
supplemented, printed out, or exported to the most frequently used image formats (PNG and JPEG). This educational software is supplemented with several interactive quizzes aimed at practising and testing Geography knowledge. Although the Mapker is already tested with teachers, it still needs some of the improvements from e-learning personalization perspective.

The key role in teaching Geography at all levels and in all types of schools, is played by cartographic materials. Even though the range of the offered Internet sources of maps is constantly growing, the search for a base map that would fully meet teacher's requirements and correspond to the lesson topic is a very protracted and often demanding process. Scanning of map images from various Geography-related publications often does not bring satisfactory results and, moreover, additional adjustment thereof (surface cut-outs, changes of used colours, adding descriptions, etc.) requires time and specific digital skills. In order to extend the value of the software design of educational resources they were reviewed and now they are being updated.

The main property of the educational software is, according to many authors, its pedagogical nature, i.e., the fact that it was designed, created, tested in practice, and further developed particularly for educational purposes, as a learning and a teaching tool (IT232 - Pedagogical software, 2009; Kalaš, 2005; Lehotská, 2007).

The most important role in learning Geography relies on the student's activity using graphical user interface (GUI), in this case, of Mapker. Therefore, the prototype of Mapker was developed with the focus to make it a user-friendly system, i.e. intuitive, efficient with pleasant, easy-to-navigate GUI. During the testing period (from April to June) the prototype of Mapker had been tried by 152 students. In order to accumulate statistics of user behaviour, while they were solving tasks, it was being tracked. In this pilot experiment, students were able to choose only two interactive activities with the aim to test their geographical knowledge.

The first activity is called "Test yourself!". It tests how a student recognizes different geographical objects in a blind map background. The system showed for each question several objects to mark but no labels (e.g. 5 different rivers). The task was to click the correct mark. After a click, the label was shown. If the answer was wrong, the correct label was shown as well. Correct and wrong labels were shown in different colours. Results, obtained within 3 months, show that the activity "Test Yourself!" was understandable, i.e. the time slot to complete the task among all the observed students was very similar, the mean was $1.02 \mathrm{~min}$. with std. deviation 0.59 . No outliers in data were detected and there was no statistically significant difference from the average performance found on that task.

The second type of task was "Hit it!". To complete this sort of task successfully, a student needed to provide an accurate and more detailed answer. This activity required a decision about the correct property of point objects position (e.g. towns) in a blind map. The task was to click as precisely as possible to a place where this object was located. After clicking, in case of a mistake, the program displayed a red flag to the clicked point and a green flag to the correct point. At the same time the score was calculated according to the distance between them in the scale from 0 to 100 points. These type activities are more sensitive, i.e. the chance of mistake was more likely to happen then in case of the activity "Test it Yourself!". Based on user behaviour data, the task "Hit it!" was completed by students in an average of 7 to 12 minutes. Besides, larger deviations from the average performance were found on that task in comparison with "Test yourself!". 
Based on the results of the pilot experiment of the Mapker's prototype it can be stated that GUI of Mapker is intuitive, but still while applying a "Hit it!" activities a deeper practical test of this type of task is needed in order to eliminate possibilities of errors regarding the requirements for the accuracy of the solution.

\section{Conclusions and Future Work}

Based on the literature review, there are different systems that might be applicable for Geography learning and teaching. However, none of them provide personalized learning. Looking at the educational system from its modernity perspective, personalized learning is the most value-promising approach. Therefore, the paper gives the analysis of e-Learning Environment for Geography and seeks to reveal opportunities for Personalized Active Learning in Geography learning. After the analysis of Mapker 3, it was found that firstly redesigning of educational resources is needed: the architecture of the system must be changed by incorporating into it a more scientific approach by not only organizing learning tasks and activities based on the commonality and variability principles but sequencing them as well. In the paper, the theoretical framework for personalized e-learning environment is discussed and future work is elaborated.

\section{References}

Baker, T. R., Bednarz, S. W. (2003). Lessons learned from reviewing research in GIS education. Journal of Geography, 102 (6): 231-233.

Baker, T. R., Kerski, J. J., Huynh, N. T., Viehrig, K., Bednarz, S. W. (2012). A call for an agenda and center for GIS education research. Research in Geographic Education Online, 2(3): 254288.

Baker, T. R., Battersby, S., Bednarz, S. W., Bodzin, A. M., Kolvoord, B., Moore, S., Sinton, D., Uttal, D. (2015). A research agenda for geospatial technologies and learning. Journal of Geography, 114 (3): 118-130.

Bodzin, A. (2011). The implementation of a geospatial information technology (GIT)-supported land use change curriculum with urban middle school learners to promote spatial thinking. Journal of Research in Science Teaching, 48(3): 281-300.

Doering, A., Veletsianos, G., Scharber, C., Miller, C. (2009). Using the technological, pedagogical, and content knowledge framework to design online learning environments and professional development. Journal of Educational Computing Research, 41 (3): 319-346.

Doering, A., Koseoglu S., Scharber, C., Henrickson, J., Lanegran, D. (2014). Technology Integration in K-12 Geography Education Using TPACK as a Conceptual Model. Journal of Geography, 113(6): 223-237. DOI:10.1080/00221341.2014.896393

Esri. 2017b. Education. http://www.esri.com/industries/education. Accessed May 13, 2019.

Goodchild, M. F., Janelle, D. G. (2010). Toward critical spatial thinking in the social sciences and humanities. Geo Journal, 75(1): 3-13.

Hummel, H. G. K., Van Den Berg, B., Berlanga, A. J., Drachsler, H., Janssen, J., Nadolski, R., Koper, R. (2007). Combining social-based and information-based approaches for personalised recommendation on sequencing learning activities. International Journal of Learning Technology, 3(2): 152-168.

IT232 - Pedagogical software. http://www.idi.ntnu.no/ terjery/IT232/EnglishIT232.html. Accessed May 10, 2019.

Jadallah, M., Hund, A. M., Thayn, J., Studebaker, J. G., Roman, Z. J. Kirby, E. (2017). Integrating Geospatial Technologies in Fifth-Grade Curriculum: Impact on Spatial Ability and MapAnalysis Skills. Journal of Geography, 116 (4): 139-151. DOI:10.1080/00221341.2017.1285339 
Jung E. H. (2017). Designing GIS learning materials for K-12 teachers. Technology, Pedagogy and Education, 26(3): 323-345. DOI: 10.1080/1475939X.2016.1224777

Karolčík, Š. (2007). Multimediálny CD-ROM (DVD-ROM) vo vyučovaní geografie (2 čast'). Geografia, 15(1): 33-38.

Karolčík, Š. (2010). Digitálne technológie vo vyučovaní geografie. Geografia, 18(3):106-112.

Karolčík, Š., Čipková, E., Hrušecký, R., Veselský, M. (2015). The Comprehensive Evaluation of Electronic Learning Tools and Educational Software (CEELTES). Informatics in Education, 14(2): 243-264. DOI: 10.15388/infedu.2015.14

Karolčík, Š., Čipková, E., Mázorová, H. (2016). Application of digital technologies in the geography teaching process from the teachers' perspective. International Research in Geographical and Environmental Education, 25(4): 328-343. DOI: $10.1080 / 10382046.2016 .1207992$

Knutov, E., De Bra, P., Pechenizkiy, M. (2009). AH 12 years later: a comprehensive survey of adaptive hypermedia methods and techniques. New Review of Hypermedia and Multimedia, 15(1): 5-38.

Lee, J., R. S. Bednarz. (2009). Effect of GIS learning on spatial thinking. Journal of Geography in Higher Education, 33(2): 183-198.

McClurg, P. A., Buss, A. (2007). Professional development: Teachers use of GIS to enhance student learning. Journal of Geography, 106 (2): 79-87.

NASA WorldWind. (2017). About/NASA WorldWind. https://worldwind.arc.nasa.gov/about/ Accessed October 13, 2018.

National Research Council. (2006). Learning to Think Spatially. Washington, D.C.: National Academies Press.

NGSS Lead States. (2013). Next Generation Science Standards: For States, By States. Washington, D.C.: National Academies Press.

Niu, N., Easterbrook, S. (2009). Concept analysis for product line requirements. Proceedings of the 8th ACM international conference on Aspect-oriented software development (AOSD), $137-148$.

Schultz, R. B., Kerski, J. J., Patterson, T. C. (2008). The use of virtual globes as a spatial teaching tool with suggestions for metadata standards. Journal of Geography, 107(1): 27-34. DOI: $10.1080 / 00221340802049844$

Skyline (2017). Skyline Software Systems: Skyline Globe 3D earth software solutions. http://www.skylineglobe.com/SkylineGlobe/corporate/Products/te_desktop.aspx. Accessed October 13, 2018.

van Merriënboer, J., Kirschner, P. (2018). Ten Steps to Complex Learning. New York: Routledge, https://doi.org/10.4324/9781315113210

Wilson, T. (2008). OGC KML. http://portal.opengeospatial.org/files/?artifact id=27810. Accessed October 20, 2018.

Zhu, L., Pan, X., Gao, G. (2016). Assessing Place Location Knowledge Using a Virtual Globe. Journal of Geography, 115(2): 72-80, DOI: 10.1080/00221341.2015.1043930

\section{Authors' information}

Štefan Karolčík, PhD - associate professor, head of Department of Didactics in Science, Psychology and Pedagogy, Faculty of Natural Sciences of Comenius University in Bratislava. His research experience is in the areas of educational system and education methods, specially in digital technologies and the implementation thereof in the teaching and learning processes. The author and publisher of several original musical CD's, interactive multimedia encyclopedias and specialized program applications. He also consulted as an expert in curriculum development, textbook writing, teacher education and development with institutions and schools in Slovakia. 
Inga Zilinskiene received her Ph.D. degree in informatics engineering from Vilnius University in 2013. She is an Associate Professor at Mykolas Romeris University. Her research interests relate to technology-enhanced learning (e-learning) domain, in particular: 1) ICT for education and learning personalisation; 2) evaluation of e-learning quality in respect of learning objects, repositories, activities, virtual learning environments etc.

Asta Slotkiene received her Ph.D. degree in informatics engineering from Kaunas University of Technology in 2009. Currently she is a lecturer at Vilnius Gediminas Technical University. Her research experience is related to design and development of smart learning objects (SLO), and application of SLO metadata for personalization.

Elena Čipková, $\mathrm{PhD}$ - associate professor, is currently working as a lecturer at the Department of Didactics in Science, Psychology and Pedagogy, Faculty of Natural Sciences of Comenius University in Bratislava, Slovakia. She lectures courses Technique and Didactics of Biology School Experiments and Digital Technologies in Education. She is an expert in curriculum design and textbook writing. Her research experiences are in the areas of biology education, educational system and education technologies. 